\title{
Irinotecan plus cisplatin followed by octreotide long- acting release maintenance treatment in advanced gastroenteropancreatic neuroendocrine carcinoma: IPO-NEC study
}

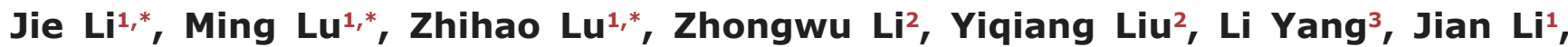 \\ Xiaotian Zhang ${ }^{1}$, Jun Zhou ${ }^{1}$, Xicheng Wang ${ }^{1}$, Jifang Gong ${ }^{1}$, Jing Gao ${ }^{1}$, Yan Li $^{1}$ and \\ Lin Shen ${ }^{1}$ \\ ${ }^{1}$ Department of GI Oncology, Key laboratory of Carcinogenesis and Translational Research (Ministry of Education), Peking \\ University School of Oncology, Beijing Cancer Hospital \& Institute, Beijing, China \\ 2 Department of Pathology, Key laboratory of Carcinogenesis and Translational Research (Ministry of Education), Peking \\ University School of Oncology, Beijing Cancer Hospital \& Institute, Beijing, China \\ ${ }^{3}$ Center of clinical oncology, The University of Hong Kong-Shenzhen Hospital, Shenzhen, China \\ * These authors have contributed equally to this work \\ Correspondence to: Lin Shen, email: lin100@medmail.com.cn
}

Keywords: gastroenteropancreatic neuroendocrine carcinomas; irinotecan; cisplatin; octreotide long-acting release; heterogeneous

Received: February 21, $2016 \quad$ Accepted: October 16, $2016 \quad$ Published: October 25, 2016

Copyright: Li et al. This is an open-access article distributed under the terms of the Creative Commons Attribution License (CC-BY), which permits unrestricted use, distribution, and reproduction in any medium, provided the original author and source are credited.

\section{ABSTRACT}

There have been very few prospective studies of first-line chemotherapy on advanced gastroenteropancreatic neuroendocrine carcinoma (GEP-NEC). This phase II study assessed the activity and safety of irinotecan plus cisplatin (IP) followed by octreotide long-acting release (LAR) maintenance treatment in advanced GEP-NEC. Forty patients were treated and eighteen patients $(45.0 \%)$ had a partial response. The median progression-free survival (PFS) and overall survival (OS) were 5.7 months and 12.9 months, respectively. Because GEP-NECs are heterogeneous, a subgroup analysis was conducted by dividing all patients into a high proliferation neuroendocrine tumor (NET) group (well differentiated neuroendocrine neoplasms with a Ki-67 level between $\mathbf{2 0 - 6 0 \% )}$ or a poorly differentiated NEC (PDNEC) group. Compared with the PDNEC group, the patients in high proliferation NET group had a lower response rate ( $0 \%$ versus $51.4 \%)$ but longer PFS ( 8.9 versus 5.7 months) and received more octreotide LAR treatment (median cycles, 7 versus 3 ). The most common toxicities included grade $3 / 4$ leukopenia/neutropenia $(60 \%)$, nausea/vomiting $(17.5 \%)$ and diarrhea $(12.5 \%)$. Therefore, IP is an active regimen in patients with advanced GEPPDNEC and should probably not be given to patients with advanced high proliferative NET. The benefit of octreotide LAR maintenance therapy on high proliferation NETs requires further study.

\section{INTRODUCTION}

Gastroenteropancreatic neuroendocrine tumors (GEP-NETs) are a heterogeneous group of neoplasms arising from the diffuse neuroendocrine system. According to the 2010 World Health Organization (WHO) classification [1], neuroendocrine tumors are classified histologically based on tumor differentiation (well or poorly differentiated) and tumor grade (grades 1-3).
Poorly differentiated or grade 3 neuroendocrine tumors, which are also called neuroendocrine carcinoma (NEC), have a mitotic count exceeding 20/10 high-power field (HPF) and/or a Ki-67 index exceeding 20\%.

Although previously regarded as rare, the incidence of GEP-NEC has recently started to increase [2-6], likely due to more precise pathologic classification. Most GEPNECs are metastatic at the time of diagnosis, and the patient prognosis is always dismal $[7,8]$. Guidelines for 
the treatment of advanced GEP-NEC advocate the use of platinum-based chemotherapy combined with etoposide [9-12]. However, until recently, only a few small first-line studies have been reported, and the objective response rate (ORR) to the EP regimen for advanced GEP-NECs varies greatly from $14 \%$ to $67 \%$ [13-15].

In 2002, a clinical trial demonstrated that an irinotecan/cisplatin (IP) regimen achieved better survival than the EP regimen in extensive small cell lung cancer (SCLC) patients [16]. Our retrospective study has also revealed that the ORR of IP chemotherapy was $57.1 \%$, with a disease control rate of $78.6 \%$ in advanced GEPNEC patients [17]. Although quite chemo-sensitive, advanced GEP-NECs are always aggressive with short progression-free survival (PFS) and overall survival (OS) times. A procedure that maintains a good response to IP treatment and improves the OS has yet to be determined.

Somatostatin analogs, initially used for the treatment of carcinoid syndrome [18-20], have recently been shown to have anti-proliferative activity [21-23]. In our retrospective study [17], octreotide long-acting release (LAR) was administered as maintenance treatment for patients in which the disease was controlled after an irinotecan/cisplatin regimen. All patients tolerated the octreotide LAR treatment well. The median number of cycles of octreotide LAR was 4.5 (3-20 cycles), which showed that octreotide LAR may be a good option for maintenance treatment.

Hence, we conducted this phase II trial (ClinicalTrials.gov Identifier: NCT01480986) with the aim of investigating the activity and safety of IP treatment and subsequent octreotide LAR treatment as a first-line approach in the treatment of patients with advanced GEPNECs.

\section{RESULTS}

\section{Patient characteristics}

The study was activated in August 2011 and closed to patient accrual in December 2013. Forty patients were enrolled. Table 1 shows the characteristics of the enrolled patients. In order to guarantee the quality of the trial, all the 5 patients with unknown primary tumor had been reviewed and approved by the multidisciplinary team (MDT) during the screening period. Last follow-up was in December 2014.

\section{Treatment received}

The total number of IP regimen cycles for all the paitents was 155 , with a median of 4 for each patient. Ten patients $(25.0 \%)$ received only one cycle of IP treatment due to rapid tumor progression (one patient) and treatment-related toxicity (two patients with febrile neutropenia, grade 3 thrombocytopenia and grade 3 diarrhea and seven patients with a treatment delay of more than 2 weeks due to toxicity). Three patients who had locally advanced disease received an R0 resection after systemic treatment. Seventeen patients $(42.5 \%)$ completed the planned six cycles of IP chemotherapy, and 12 went on to receive octreotide LAR according to the protocol. Four patients received octreotide LAR as maintenance treatment following discontinuing chemotherapy due to severe toxicities. Table 2 shows the characteristics and clinical outcomes of patients with octreotide LAR maintenance treatment. The median number of octreotide LAR cycles was 3 (1-25 cycles). Due to a change in the pharmaceutical dosage forms in China, 6 patients received octreotide LAR (30 mg). Of the 16 patients who received maintenance octreotide LAR, 1 patient received only one dose of octreotide LAR due to intolerable diarrhea, 2 patients discontinued the drug due to financial problems, and the remaining 13 patients continued octreotide LAR treatment until the disease progressed.

After disease progression, the patients were given a variety of palliative treatments including radiotherapy (5 patients, $12.5 \%$ ), octreotide LAR treatment (2 patients, $5.0 \%)$, transcatheter arterial chemoembolization (7 patients, 17.5\%) and salvage chemotherapy (9 patients, $22.5 \%$ ). Salvage chemotherapy regimens consisted of combined chemotherapy including irinotecan with platinum (5 patients, who had got PR or MR in the first line IP treatment), etoposide with platinum, and temozolomide with capecitabine; the single agents included paclitaxel, irinotecan, etoposide and capecitabine.

\section{Response to treatment}

A total of 32 patients were evaluable for tumor response. (Table 3) No patient achieved a complete response (CR); eighteen $(18 / 40,45.0 \%)$ patients had a partial response (PR) and $10(10 / 40,25.0 \%)$ had stable disease (SD). The disease control rate (DCR) was $70.0 \%$. The response rate to IP treatment in esophageal NEC, gastric NEC, and pancreatic NEC was $62.5 \%, 40.0 \%$ and $16.7 \%$, respectively $(p=0.253)$. The median PFS was 5.7 months (95\% confidence interval: 3.8-7.6 months), and the median OS was 12.9 months (95\% confidence interval: 10.5-15.4 months) for the entire group. (Figure 1) For the 37 patients who haven't received surgery following IP chemotherapy, the median PFS was 5.6 months (95\% confidence interval: 4.3-6.9 months), and the median OS was 12.8 months (95\% confidence interval: 10.7-15.0 months).

According to the 2013 Chinese gastrointestinal and pancreatic neuroendocrine neoplasms pathologic consensus [24], compared with the patients in poorly 
Table 1: Patient demographics and clinical characteristics

\begin{tabular}{|c|c|c|}
\hline Variables & Number of patients & Proportion (\%) \\
\hline \multicolumn{3}{|l|}{ Gender } \\
\hline Male & 30 & 75.0 \\
\hline Female & 10 & 25.0 \\
\hline \multicolumn{3}{|c|}{ Age [median (range)], 56.5 (30-77) } \\
\hline$<59$ & 25 & 62.5 \\
\hline$\geq 60$ & 15 & 37.5 \\
\hline \multicolumn{3}{|c|}{ Karnofsky performance score(KPS) } \\
\hline$<90$ & 19 & 47.5 \\
\hline$\geq 90$ & 21 & 52.5 \\
\hline \multicolumn{3}{|l|}{ Location of primary tumor } \\
\hline Stomach & 15 & 37.5 \\
\hline Esophagus & 8 & 20.0 \\
\hline Pancreas & 6 & 15.0 \\
\hline Colorectum & 4 & 10.0 \\
\hline Small intestine & 2 & 5.0 \\
\hline Unknown primary origin & 5 & 12.5 \\
\hline \multicolumn{3}{|l|}{ Histology } \\
\hline Small cell NEC & 20 & 50.0 \\
\hline Large cell NEC & 8 & 20.0 \\
\hline MANEC & 7 & 17.5 \\
\hline High proliferation NET & 5 & 12.5 \\
\hline \multicolumn{3}{|c|}{ Immunohistochemistry(positive/total) } \\
\hline Synaptophysin & $36 / 40$ & 90.0 \\
\hline Chromogranin A & $25 / 39$ & 64.1 \\
\hline CD56 & $25 / 39$ & 64.1 \\
\hline \multicolumn{3}{|l|}{ Ki-67 } \\
\hline$\geq 75 \%$ & 21 & 52.5 \\
\hline $50-74 \%$ & 9 & 22.5 \\
\hline $20-49 \%$ & 8 & 20.0 \\
\hline Unknown & 2 & 5.0 \\
\hline \multicolumn{3}{|l|}{ Carcinoid syndrome } \\
\hline Yes & 3 & 7.5 \\
\hline No & 37 & 92.5 \\
\hline \multicolumn{3}{|l|}{ Octreotide scanning } \\
\hline Positive & 19 & 47.5 \\
\hline Negative & 20 & 50.0 \\
\hline Unknown & 1 & 2.5 \\
\hline \multicolumn{3}{|l|}{ Stage } \\
\hline Locally advanced & 5 & 12.5 \\
\hline Metastatic & 35 & 87.5 \\
\hline \multicolumn{3}{|l|}{ Metastasis } \\
\hline Liver & 25 & 62.5 \\
\hline Lung & 3 & 7.5 \\
\hline Bone & 5 & 12.5 \\
\hline Distant lymph nodes & 29 & 72.5 \\
\hline \multicolumn{3}{|c|}{ Serum NSE level before treatment } \\
\hline$<50 \mathrm{ng} / \mathrm{ml}$ & 21 & 52.5 \\
\hline$\geq 50 \mathrm{ng} / \mathrm{ml}$ & 17 & 42.5 \\
\hline unknown & 2 & 5 \\
\hline \multicolumn{3}{|c|}{ Serum LDH level before treatment } \\
\hline$<300 \mathrm{U} / \mathrm{ml}$ & 29 & 72.5 \\
\hline$\geq 300 \mathrm{U} / \mathrm{ml}$ & 11 & 27.5 \\
\hline
\end{tabular}

*Abbreviations: $\mathrm{NEC}=$ neuroendocrine carcinoma; $\mathrm{MANEC}=$ mixed adenoneuroendocrine carcinoma; $\mathrm{NET}=$ neuroendocrine tumor; $\mathrm{NSE}=$ neuron-specific enolase; $\mathrm{LDH}=$ lactic dehydrogenase. 
Table 2: Characteristics and clinical outcomes of patients with advanced GEP-NEC receiving octreotide LAR maintenance treatment

\begin{tabular}{|c|c|c|c|c|c|c|c|c|c|c|c|}
\hline \multirow[b]{2}{*}{ No } & \multirow{2}{*}{$\begin{array}{l}\text { Gender } \\
\text { /age }\end{array}$} & \multirow[b]{2}{*}{ Histology } & \multirow{2}{*}{$\begin{array}{l}\text { Octreatide } \\
\text { scan }\end{array}$} & \multirow{2}{*}{$\begin{array}{l}\text { Primary } \\
\text { site }\end{array}$} & \multirow{2}{*}{$\begin{array}{l}\text { Metastatic } \\
\text { sites }\end{array}$} & \multirow{2}{*}{$\begin{array}{l}\text { IP } \\
\text { cycles }\end{array}$} & \multirow{2}{*}{$\begin{array}{l}\text { IP } \\
\text { response }\end{array}$} & \multicolumn{3}{|c|}{ Octreotide LAR } & \multirow{2}{*}{$\begin{array}{l}\text { PFS } \\
\text { (m) }\end{array}$} \\
\hline & & & & & & & & Cycles & $\begin{array}{l}\text { Dosage } \\
\text { (mg) }\end{array}$ & $\begin{array}{ll}\begin{array}{l}\text { Reasons } \\
\text { interruption }\end{array} & \text { for } \\
\end{array}$ & \\
\hline 1 & $\mathrm{~F} / 63$ & L-NEC & Positive & Pancreas & Liver, LNs & 1 & NA & 3 & 20 & PD & 3.27 \\
\hline 2 & $\mathrm{M} / 55$ & L-NEC & Positive & colorectum & Cervical LNs & 6 & PR & 3 & 20 & Financial problem & 14 \\
\hline 3 & $\mathrm{~F} / 66$ & S-NEC & Negative & Stomach & Liver, Lung, LNs & 6 & PR & 3 & 20 & PD & 5.63 \\
\hline 4 & $\mathrm{M} / 56$ & S-NEC & Positive & Unknown & \begin{tabular}{|l|}
$\begin{array}{l}\text { Pelvic } \\
\text { inguinal LNs }\end{array}$ \\
\end{tabular} & 4 & PR & 25 & 20 & PD & 26.5 \\
\hline 5 & $\mathrm{M} / 59$ & S-NEC & Negative & Unknown & Liver, Bone, LNs & 6 & PR & 3 & 20 & PD & 6.9 \\
\hline 6 & $\mathrm{M} / 51$ & MANEC & Negative & Esophagus & Lung, Bone, LNs & 6 & SD & 1 & 20 & $\mathrm{PD}$ & 4.57 \\
\hline 7 & $\mathrm{M} / 57$ & MANEC & Positive & Stomach & Liver, LNs & 6 & PR & 2 & 20 & PD & 4.53 \\
\hline 8 & $\mathrm{~F} / 48$ & MANEC & Negative & Stomach & \begin{tabular}{|l|} 
Celiac and \\
retroperitoneal \\
LNs \\
\end{tabular} & 6 & PR & 8 & 20 & PD & 12.3 \\
\hline 9 & $\mathrm{M} / 67$ & MANEC & Negative & Stomach & Liver & 6 & PR & 5 & 20 & $\mathrm{PD}$ & 7.37 \\
\hline 10 & $\mathrm{M} / 30$ & H-NET & Positive & Pancreas & Liver, Bone, LNs & 6 & SD & 5 & 20 & $\mathrm{PD}$ & 8.93 \\
\hline 11 & $\mathrm{M} / 54$ & MANEC & Positive & Stomach & $\begin{array}{l}\text { Supraclavicular } \\
\text { Celiac, } \\
\text { retroperitoneal } \\
\text { and pelvic LNs } \\
\end{array}$ & 6 & PR & 1 & 30 & PD & 3.7 \\
\hline 12 & $\mathrm{M} / 54$ & L-NEC & Positive & Pancreas & Liver, LNs & 6 & PR & 1 & 30 & Severe diarrhea & 5.6 \\
\hline 13 & $\mathrm{~F} / 63$ & S-NEC & Negative & Unknown & Lung, LNs & 3 & PR & 4 & 30 & PD & 5.27 \\
\hline 14 & $\mathrm{M} / 48$ & S-NEC & Positive & Pancreas & Liver, LNs & 6 & SD & 4 & 30 & $\mathrm{PD}$ & 7.6 \\
\hline 15 & $\mathrm{M} / 56$ & S-NEC & Positive & Stomach & Liver, LNs & 6 & PR & 3 & 30 & PD & 8.17 \\
\hline 16 & $\mathrm{~F} / 55$ & H-NET & Negative & Stomach & Liver, LNs & 4 & SD & 9 & 30 & Financial problem & 14.9 \\
\hline
\end{tabular}

*Abbreviations: $\mathrm{F}=$ female; $\mathrm{M}=$ male; $\mathrm{L}-\mathrm{NEC}=$ large cell neuroendocrine carcinoma; $\mathrm{S}-\mathrm{NEC}=$ small cell neuroendocrine carcinoma; H-NET = high proliferation neuroendocrine tumor; MANEC $=$ mixed adenoneuroendocrine carcinoma; $\mathrm{LN}=1 \mathrm{ymph}$ node; $\mathrm{IP}=$ irinotecan plus cisplatin; $\mathrm{SD}=$ stable disease; $\mathrm{PR}=$ partial response; $\mathrm{LAR}=$ long-acting release; $\mathrm{PD}=\mathrm{progression}$ disease; $\mathrm{NA}=$ Not applicable; $\mathrm{m}=$ month.

Table 3: Clinical outcomes of IP chemotherapy in patients with advanced GEP-NEC by different histological subtypes

\begin{tabular}{|c|c|c|c|c|c|c|c|}
\hline \multirow[b]{2}{*}{ Histology } & \multicolumn{6}{|c|}{ Response to IP regimen } & \multirow[b]{2}{*}{$\begin{array}{l}\text { PFS } \\
\text { (months) }\end{array}$} \\
\hline & $\begin{array}{l}\text { No.of } \\
\text { CR }(\%)\end{array}$ & $\begin{array}{l}\text { No.of } \\
\operatorname{PR}(\%)\end{array}$ & $\begin{array}{c}\text { No.of } \\
\text { SD (\%) }\end{array}$ & \begin{tabular}{|l|} 
No.of \\
PD (\%)
\end{tabular} & \begin{tabular}{|l|} 
No.of \\
NA (\%)
\end{tabular} & $\begin{array}{c}\text { Disease control } \\
\text { rate }(\%)\end{array}$ & \\
\hline Small cell NEC $(n=20)$ & 0 & $11(55.0)$ & $3(15.0)$ & 0 & $6(30.0)$ & 70.0 & 6.9 \\
\hline Large cell NEC $(n=8)$ & 0 & $3(37.5)$ & $2(25.0)$ & $2(25.0)$ & $1(12.5)$ & 62.5 & 5.6 \\
\hline MANEC $(n=7)$ & 0 & $4(57.1)$ & $1(14.3)$ & $1(14.3)$ & $1(14.3)$ & 71.4 & 4.5 \\
\hline High proliferation NET $(n=5)$ & 0 & 0 & $4(80.0)$ & $1(20.0)$ & 0 & 80.0 & 8.9 \\
\hline All patients $(n=40)$ & 0 & $18(45.0)$ & $10(25.0)$ & $4(10.0)$ & $8(20.0)$ & 70.0 & 5.7 \\
\hline
\end{tabular}

*Abbreviations: $\mathrm{IP}=$ irinotecan plus cisplatin; $\mathrm{PFS}=$ progression-free survival; $\mathrm{CR}=$ complete response; $\mathrm{PR}=$ partial response; $\mathrm{SD}=$ stable disease; $\mathrm{PD}=$ progression disease; $\mathrm{NA}=$ Not applicable; $\mathrm{NEC}=$ neuroendocrine carcinoma; $\mathrm{MANEC}=$ mixed adenoneuroendocrine carcinoma; NET = neuroendocrine tumor.

differentiated NEC (PDNEC) group, the patients with high proliferation neuroendocrine tumor (NET) had a lower ORR ( $0 \%$ versus $51.4 \%, p=0.053)$ but longer PFS (8.9 versus 5.7 months) and received more octreotide LAR treatment (median cycles, 7 versus 3 ). (Table 2 and Table 3)

\section{Toxicities}

The IP regimen-related toxicities are summarized in Table 4. Grade 3/4 leukopenia/neutropenia was observed in 24 patients $(60.0 \%)$, and 3 patients $(7.5 \%)$ experienced febrile neutropenia. Grade 3/4 thrombocytopenia occurred in 2 patients $(5.0 \%)$. No grade $3 / 4$ hematological toxicity was observed during the octreotide LAR maintenance treatment.

Seven patients $(17.5 \%)$ suffered from grade 3 nausea/vomiting, 5 patients $(12.5 \%)$ experienced grade 3 diarrhea, 2 patients $(5.0 \%)$ exhibited grade 3 anorexia, 2 patients $(5.0 \%)$ had grade 3 alopecia and one patient $(2.5 \%)$ had severe fatigue. All other toxicities were mild. Only 1 patient experienced grade 3 diarrhea during 
Table 4: Chemotherapy-related toxicity after IP chemotherapy $(\mathrm{N}=40 ; 155$ treatment cycles)

\begin{tabular}{|c|c|c|c|}
\hline Toxicity & $\begin{array}{c}\text { All grades } \\
\text { Patients, } n(\%)\end{array}$ & $\begin{array}{c}\text { Grade } 3 \\
\text { Patients, } n(\%)\end{array}$ & $\begin{array}{c}\text { Grade } 4 \\
\text { Patients, } n(\%)\end{array}$ \\
\hline \multicolumn{4}{|l|}{ Hematologic } \\
\hline Leukopenia/Neutropenia & $35(87.5)$ & $14(35.0)$ & $10(25.0)$ \\
\hline Anemia & $20(50.0)$ & $1(2.5)$ & $0(0)$ \\
\hline Thrombocytopenia & $14(35.0)$ & $2(5.0)$ & $0(0)$ \\
\hline Neutropenic fever & $3(7.5)$ & NA & NA \\
\hline \multicolumn{4}{|l|}{ Non-hematologic } \\
\hline AST/ALT & $6(15.0)$ & $0(0)$ & $0(0)$ \\
\hline Fatigue & $18(45.0)$ & $1(2.5)$ & $0(0)$ \\
\hline Neurological sensory & $6(15.0)$ & $0(0)$ & $0(0)$ \\
\hline Acute cholinergic syndrome & $13(32.5)$ & $0(0)$ & $0(0)$ \\
\hline Nausea/ Vomiting & $39(97.5)$ & $7(17.5)$ & $0(0)$ \\
\hline Diarrhea & $19(47.5)$ & $5(12.5)$ & $0(0)$ \\
\hline Anorexia & $25(62.5)$ & $2(5.0)$ & $0(0)$ \\
\hline Mucositis & $3(7.5)$ & $0(0)$ & $0(0)$ \\
\hline Alopecia & $17(42.5)$ & $2(5.0)$ & $0(0)$ \\
\hline
\end{tabular}

*Abbreviations: AST= aspartate aminotransferase; $\mathrm{ALT}=$ alanine aminotransferase; $\mathrm{NA}=$ Not applicable.

octreotide LAR maintenance treatment. Due to the toxicity, nine patients $(22.5 \%)$ received only one cycle of IP treatment, and fourteen patients (35\%) received a dose reduction. No other unexpected toxicities were observed, and no treatment-related death was reported.

\section{DISCUSSION}

Advanced GEP-NEC patients have a poor prognosis. The median survival for patients receiving chemotherapy was 11 months, and for patients without chemotherapy the survival time was only 1 month [7], suggesting that those patients should be considered for chemotherapy without delay.

Many guidelines advocate the use of platinumbased chemotherapy combined with etoposide for the treatment of patients with GEP-NEC, similar to the treatment of small cell lung cancer [9-12]. However, the efficacy of this treatment varies in different studies [1315]. Mitry et al. [14] retrospectively analyzed the efficacy of the EP regimen in 41 NEC patients; the ORR was $41.5 \%$ (4 CR and 13 PR). Grade 3-4 hematological toxicity was observed in $60 \%$ of the cases with one treatment-related death. In a recent retrospective study [7], 252 patients with advanced GEP-NEC received cisplatin/etoposide or carboplatin/etoposide; the ORR was only $31 \%$, and the median PFS and OS were 4 and 11 months, respectively. Moreover, in a Japanese retrospective study [15], 21 hepato-biliary-pancreatic NEC patients were treated with EP as a first-line chemotherapy; the ORR, median PFS and OS were only $14 \%$ and 1.8 and 5.8 months, respectively, and grade 3 or 4 neutropenia was observed in $90 \%$ of these patients.

The JCOG9511 study demonstrated significantly longer OS in the IP arm than in the EP arm for SCLC
[16]. In our retrospective analysis of 16 advanced GEPNEC patients treated with IP, the median PFS and OS were 5.5 and 10.6 months, respectively [17]. Recently, a retrospective Japanese multicenter analysis [25] showed that for patients with advanced NEC of the digestive system including gastrointestinal tract and hepato-biliarypancreatic system treated with IP/EP $(n=160 / 46)$, the ORR were $50 \% / 28 \%$ and the median OS times were $13.0 /$ 7.3 months. A multivariate analysis among patients treated with IP or EP showed a tendency that the efficacy of IP was slightly better than that of EP (HR $0.80,95 \%$ CI 0.48 $1.33 ; p=0.389$ ). In this prospective study, IP as a firstline therapy for advanced stage GEP-NEC resulted in an ORR of $45.0 \%$, a median PFS of 5.7 months and a median OS of 12.9 months, which showed that IP was an active regimen in these patients. Due to the IP treatment-related toxicity, the treatment interruption and dose reduction rates were high. Hence, dose adjustment is necessary in future studies.

To maintain a good response to IP treatment, we searched for an antitumor agent that could be administered for a long period of time with little toxicity. Somatostatin analogs can exert antitumor effects by both direct and indirect mechanisms [26]. A placebo-controlled phase IIIB study (PROMID) [23] demonstrated that octreotide significantly lengthened the time to tumor progression compared to a placebo in patients with treatment-naive metastatic well-differentiated midgut NETs. CLARINET study [27] found Lanreotide was also associated with significantly prolonged progression-free survival among patients with metastatic enteropancreatic neuroendocrine tumors of grade 1 or 2 (Ki-67<10\%). Till now, there are no data supporting the use of somatostatin analogs in GEP-NEC [6]. Zarogoulidis $\mathrm{K}$ et al. found that long acting somatostatin analogues could be used as an additive 
therapy in combination to antineoplastic agents in patients with SCLC positive for somatostatin receptors [28]. Our retrospective analysis showed that octreotide LAR may be a good option for maintenance treatment [17]. In this prospective study, sixteen patients received octreotide LAR as maintenance treatment. The median cycle (3 cycles) of octreotide LAR treatment was less than that in our retrospective study, and 7 patients received more than three cycles of treatment. Among those patients, one patient with postive Octreatide-Scan received as many as 25 cycles of octreotide LAR, and two patients with negative Octreatide-Scan had 8 and 9 cycles. So, Octreotide LAR did have antitumor effect on the two NEC patients with negative Octreatide-Scan. Indirect antitumor effects of somatostatin analogs, independent of somatostatin receptors, might include inhibition of growth-promoting hormone and growth factor secretion, and antiangiogenic actions [26]. However, due to the insufficient numbers of the population, we can unfortunately not evaluate if there is a benefit of adding octreotide as maintenance therapy after chemotherapy.

According to the 2010 WHO classification, there is an assumption that poorly differentiated histology and high tumor grade are equivalent. However, Scoazec et al. [29], who investigated a series of 104 patients with large cell GEP-NECs, found that $20 \%$ of tumors were characterized as well differentiated, despite a Ki-67 index $>20 \%$. In a study of 28 patients with metastatic thoracic and GEP-NECs with a Ki-67 index > 20\%, 42.8\% of cases had histologically well differentiated tumors. Furthermore, they found that the proportion of patients with short survival ( $<2$ years) with G3 well differentiated NETs was smaller than that of patients with G3 large cell NECs (25\% versus $62.5 \%, p=0.049)$ [30]. In addition to the morphology, studies have indicated that a $\mathrm{Ki}-67$ threshold of $55 \%$ is predictive for the response to first-line platinum-based chemotherapy. Patients with a Ki-67 index $<55 \%$ had a lower ORR ( $15 \%$ versus $42 \%, p<0.001)$ to platinum-based chemotherapy, but better survival than patients with a Ki-67 index $\geq 55 \%$ (14 versus 10 months, $p<0.001$ ) [7]. These new findings imply that proliferation alone is not sufficient for the classification of high grade GEP-NECs, and the morphology should be incorporated into proliferative indices to correctly classify these neoplasms [31].

Therefore, the 2010 WHO classification may be improved to better define high grade neuroendocrine neoplasms $[6,7,31,32]$. According to the recommendations of a Chinese pathologic consensus group for gastrointestinal and pancreatic neuroendocrine neoplasms [24], all of the 40 GEP-NEC tumors in this study were re-reviewed by two pathologists independently,

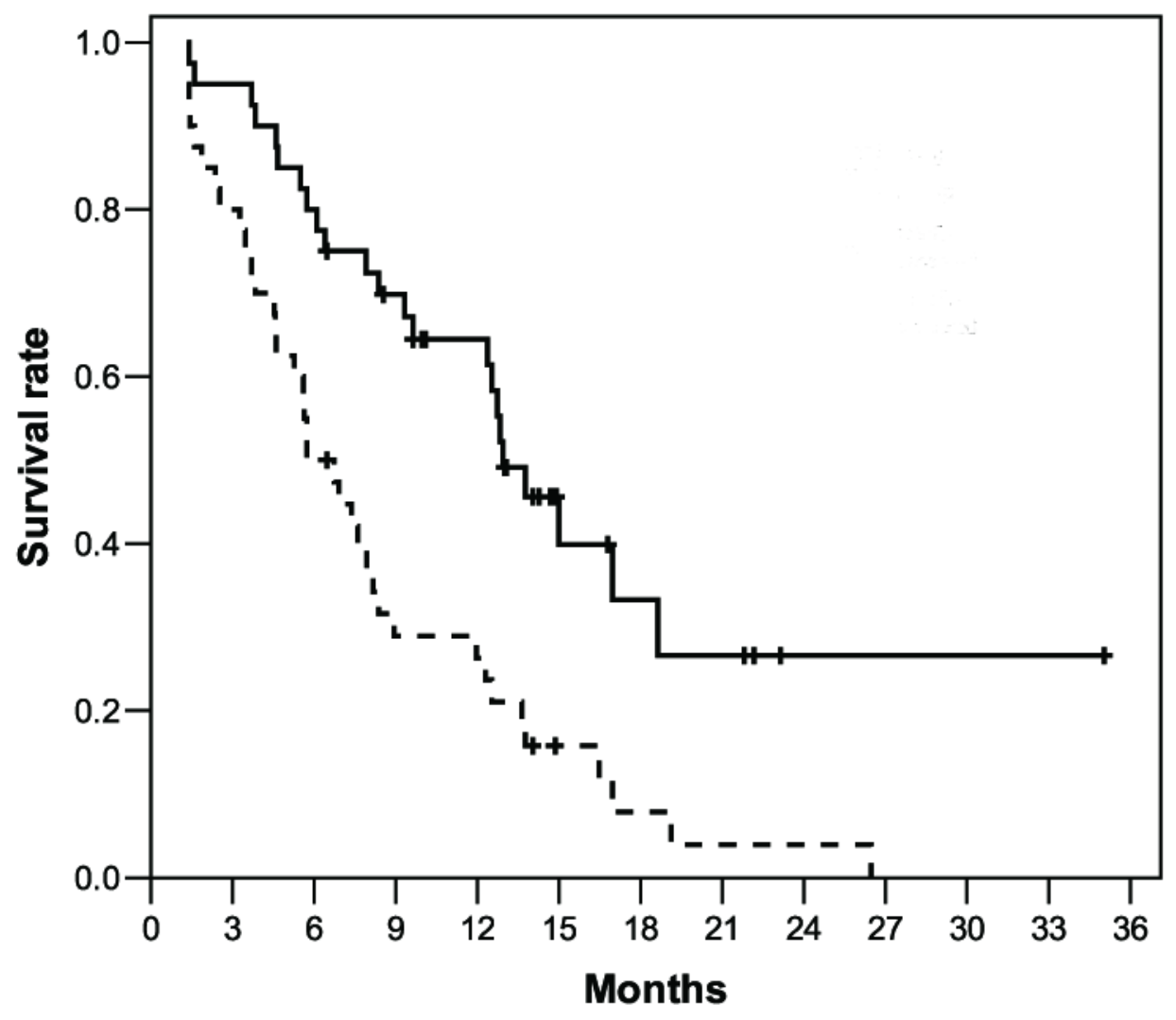

Figure 1: Overall survival (continuous line, median 12.9 months) and progression-free survival (dotted line, median 5.7 months) in the 40 patients with advanced GEP-NEC after IP treatment. 
and 5 cases were classified as high proliferation NET. This group of tumors shows remarkable differences compared with poorly differentiated GEP-NECs. First, these patients show a different response rate; patients with high proliferation NETs had a much lower ORR to IP $(0 \%)$ than patients with poorly differentiated NECs (51.4\%), which implies that platinum-based chemotherapy may be overused in patients with high proliferation NETs who might benefit from other systemic treatments, such as temozolomide-based or streptozotocin-based chemotherapy, everolimus, sunitinib or others [6, 33]. We recommend that IP treatment should only be given to G3 patients with poorly differentiated morphology. Second, these patients have different octreotide LAR maintenance cycles; patients with high proliferation NETs received more octreotide LAR maintenance cycles than patients with poorly differentiated NECs (median cycles, 7 versus 3 cycles). Although the patient numbers in these two subgroups are small, based on the biological behavior, the effect of octreotide LAR maintenance therapy on high proliferation NETs deserve further study. Third, the patients have different prognoses; although they have a lower ORR, patients with high proliferation NETs still had a longer PFS (8.9 versus 5.7 months). Therefore, it is very important to analyze the clinical diagnostic and prognostic characteristics and even the molecular pathology and genetic differences between these two subgroups to optimize the treatment of patients with advanced GEPNECs.

In conclusion, the current WHO high-grade NEC category might needs to be refined. This prospective phase II trial provides additional evidence that IP is an active regimen only in patients with advanced GEP-PDNEC and dose adjustment may be necessary due to toxicity. The observation suggests that IP should probably not be given to high proliferative NET. The benefit of octreotide LAR maintenance therapy on high proliferation NETs requires further study. Future research should focus on these preliminary results in large-scale, randomized trials to assess the ability to improve the treatment response and prognosis of patients with advanced GEP-NECs.

\section{PATIENTS AND METHODS}

\section{Study design}

This was an investigator-initiated, open-label, single-arm phase II clinical study. The primary end point of the study was PFS, which was defined as the time from the date of first treatment until the date of tumor progression or death. The secondary end points included OS, ORR and safety. The OS was defined as the time from the date of first treatment until the date of death. The study was approved by the Medical Ethics Committee of
Peking University Cancer Hospital (Beijing, China) and was performed according to the Declaration of Helsinki Principles. Written informed consent was obtained from all patients before inclusion in the study.

\section{Patients}

All patients were enrolled from Peking University Cancer Hospital. Eligible patients had locally inoperable or metastatic, histologically confirmed diagnosis of NEC (Ki-67 index $>20 \%$ and/or mitotic count exceeding 20/10 $\mathrm{HPF}$ ), including mixed adenoneuroendocrine carcinoma (MANEC) if the gland-forming elements exceed 30\%, with a gastroenteropancreatic primary or an unknown primary tumor predominantly with gastroenteropancreatic metastases. Additional inclusion criteria consisted of a Karnofsky performance score (KPS) $\geq 70$; at least one radiologically measurable lesion; no previous chemotherapy and adequate bone marrow function; adequate hepatic and renal function; a life expectancy $\geq 90$ days; and $\geq 18$ years of age. The exclusion criteria consisted of pregnant or nursing women, uncontrolled severe diarrhea, confirmed or suspected central nervous system metastasis, and a history of myocardial infarction within the past 6 months.

In 2013, a Chinese pathologic consensus group for gastrointestinal and pancreatic neuroendocrine neoplasms proposed a new entity called "high proliferation neuroendocrine tumor (NET)", which is defined as well differentiated neuroendocrine neoplasms with a Ki-67 level between 20-60\% [24]. All of the GEP-NEC tumors in this study were re-reviewed by two pathologists independently for the new classification.

\section{Pretreatment evaluation}

Pre-treatment evaluations included documentation of a routine history, a physical examination, KPS, a complete blood count (CBC), a chemistry profile, measurement of neuron-specific enolase (NSE) and electrocardiography. Tumor staging with computed tomography (CT) scans of the chest and abdomen was required. A magnetic resonance imaging (MRI) scan of the head and octreotide scanning were also required. A bone scan was indicated if the presence of bone metastases was clinically suspected.

\section{Treatment}

All patients received combination chemotherapy with irinotecan $\left(180 \mathrm{mg} / \mathrm{m}^{2}\right)$ administered for 90 minutes by intravenous (IV) infusion (day 1) and cisplatin (50 $\mathrm{mg} / \mathrm{m}^{2}$ ) administered for 120 minutes by IV infusion (day 1). The treatment courses were repeated every 2 weeks. This regimen required hydration and prophylactic 
administration of antiemetic drugs. If a patient's neutrophil count was $\leq 1.0 \times 10^{\wedge} 9 / \mathrm{L}$, recombinant human granulocyte colony-stimulating factor (G-CSF) was administered until the neutrophil level was restored.

Responses to treatment were assessed every 6 weeks. Patients who had an objective response or stable disease would receive an additional three cycles of chemotherapy. Patients who had an objective response or stable disease after chemotherapy were treated with octreotide LAR (20 $\mathrm{mg}$, deep intramuscular injection) administered at 4-week intervals. The responses to octreotide LAR maintenance treatment were assessed every twelve weeks. Octreotide LAR was discontinued in cases of unacceptable toxicity, evidence of disease progression or patient refusal.

\section{Evaluation of the treatment response}

Serial tumor assessments, based on the Response Evaluation Criteria in Solid Tumors (RECIST 1.0), were performed every 6 weeks of treatment with a CT scan of the chest and abdomen with or without a scan of the pelvis. After discontinuation of the treatment, routine re-assessment at 6- to 8-week intervals was required for patients who withdrew from the study for reasons other than disease progression.

\section{Dose modifications}

Toxicity was graded using the National Cancer Institution (NCI) Common Toxicity Criteria Version 3.0 (CTC 3.0) by direct questioning, physical examination, measurement of the $\mathrm{CBC}$, and laboratory tests. Chemotherapy was withdrawn until the neutrophil count was $\geq 1.5 \times 10^{\wedge} 9 / \mathrm{L}$, the platelet count was $\geq 100 \times 10^{\wedge} 9 / \mathrm{L}$, diarrhea stopped and other toxicities recovered to $\leq$ grade 1. The dose of irinotecan in subsequent cycles was reduced to $75 \%$ of the planned dose if patients experienced grade 4 hematologic toxic effects or if grade 3 diarrhea developed. The dose of cisplatin was reduced to $75 \%$ of the planned dose in patients with grade 2 renal toxicity. Treatment was terminated in patients with grade 4 diarrhea, grade 3 or higher renal toxicity, grade 2 or higher pulmonary toxicity, or grade 3 or higher hepatic toxicity.

\section{Statistical methods}

The predicted PFS was the determinant of sample size. On the basis of the varied estimates of the PFS in prior studies [13-15], a PFS of 3.5 months or less was not considered worthy of further investigation. The target enrollment of 32 patients would provide an $80 \%$ power to detect a 2-months improvement in PFS with one-sided $\alpha$ of 0.05 and enrollment and follow-up periods of 2.0 and 1.0 years, respectively. To ensure an adequate number of evaluable patients, a total of 40 patients were enrolled.
SPSS (version 13.0) statistical software was used for the statistical analyses. The results are presented as descriptive statistics. The survival curves were generated using the Kaplan-Meier method.

\section{ACKNOWLEDGMENTS}

We thank all patients and their families who participated in this study.

\section{CONFLICTS OF INTEREST}

The authors declare there are no conflicts of interest to disclose.

\section{REFERENCES}

1. Bosman FT, Carneiro F, Hruban RH, Theise, ND. WHO classification of tumours of the digestive system. 4th ed. Lyon:IARC Press; 2010.

2. Korse CM, Taal BG, van Velthuysen MLF, Visser O. Incidence and survival of neuroendocrine tumours in the Netherlands according to histological grade: experience of 2 decades of cancer registry. Eur J Cancer. 2013; 49:19751983.

3. Yao JC, Hassan M, Phan A, Dagohoy C, Leary C, Mares JE, Abdalla EK, Fleming JB, Vauthey JN, Rashid A, Evans DB. One hundred years after "carcinoid": epidemiology of and prognostic factors for neuroendocrine tumors in 35,825 cases in the United States. J Clin Oncol. 2008; 26:30633072 .

4. Cho MY, Kim JM, Sohn JH, Kim MJ, Kim KM, Kim WH, Kim H, Kook MC, Park DY, Lee JH, Chang H, Jung ES, Kim HK, et al. Current trends of the incidence and pathological diagnosis of gastroenteropancreatic neuroendocrine tumors (GEP-NETs) in Korea 2000-2009: multicenter study. Cancer Res Treat. 2012; 44:157-65.

5. Fraenkel M, Kim M, Faggiano A, de Herder WW, Valk GD. Incidence of gastroenteropancreatic neuroendocrine tumours: a systematic review of the literature. Endocr Relat Cancer. 2014; 21: R153-163.

6. Sorbye H, Strosberg J, Baudin E, Klimstra DS, Yao JC. Gastroenteropancreatic high-grade neuroendocrine carcinoma. Cancer. 2014; 120:2814-2823.

7. Sorbye H, Welin S, Langer SW, Vestermark LW, Holt N, Osterlund P, Dueland S, Hofsli E, Guren MG, Ohrling K, Birkemeyer E, Thiis-Evensen E, Biagini M, et al. Predictive and prognostic factors for treatment and survival in 305 patients with advanced gastrointestinal neuroendocrine carcinoma (WHO G3): the NORDIC NEC study. Ann Oncol. 2013; 24:152-160.

8. Surveillance, Epidemiology, and End Results (SEER) Program (www.seer.cancer.gov). SEER*Stat Database: Incidence-SEER 9 Regs Research Data, November 2011 submission (1973-2010). Bethesda, MD: National Cancer 
Institute, Cancer Statistics Branch, 2013.

9. Strosberg JR, Coppola D, Klimstra DS, Phan AT, Kulke MH, Wiseman GA, Kvols LK; North American Neuroendocrine Tumor Society (NANETS). The NANETS consensus guidelines for the diagnosis and management of poorly differentiated (high-grade) extrapulmonary neuroendocrine carcinomas. Pancreas. 2010; 39:799-800.

10. Eriksson B, Annibale B, Bajetta E, Mitry E, Pavel M, Platania M, Salazar R, Plöckinger U; Mallorca Consensus Conference participants; European Neuroendocrine Tumor Society. ENETS Consensus Guidelines for the Standards of Care in Neuroendocrine Tumors: chemotherapy in patients with neuroendocrine tumors. Neuroendocrinology. 2009; 90:214-219.

11. National Comprehensive Cancer Network (NCCN). NCCN small cell lung cancer clinical practice guidelines in oncology (version 1.2016) [EB/OL]. Fort Washington: NCCN,2015 [06/02/15]. http://www.nccn.org/professionals/ physician_gls/f_guidelines.asp.

12. Janson ET, Sorbye H, Welin S, Federspiel B, Grønbæk H, Hellman P, Ladekarl M, Langer SW, Mortensen J, SchalinJäntti C, Sundin A, Sundlöv A, Thiis-Evensen E, Knigge U. Nordic Guidelines 2014 for diagnosis and treatment of gastroenteropancreatic neuroendocrine neoplasms. Acta Oncol. 2014; 53:1284-1297.

13. Moertel CG, Kvols LK, O'Connell MJ, Rubin J. Treatment of neuroendocrine carcinomas with combined etoposide and cisplatin. Evidence of major therapeutic activity in the anaplastic variants of these neoplasms. Cancer. 1991; 68:227-232.

14. Mitry E, Baudin E, Ducreux M, Sabourin JC, Rufié P, Aparicio T, Aparicio T, Lasser P, Elias D, Duvillard P, Schlumberger M, Rougier P. Treatment of poorly differentiated neuroendocrine tumours with etoposide and cisplatin. Br J Cancer. 1999; 81:1351-1355.

15. Iwasa S, Morizane C, Okusaka T, Ueno H, Ikeda M, Kondo S, Tanaka T, Nakachi K, Mitsunaga S, Kojima Y, Hagihara A, Hiraoka N. Cisplatin and etoposide as firstline chemotherapy for poorly differentiated neuroendocrine carcinoma of the hepatobiliary tract and pancreas. Jpn J Clin Oncol. 2010; 40:313-318.

16. Noda K, Nishiwaki Y, Kawahara M, Negoro S, Sugiura T, Yokoyama A, Fukuoka M, Mori K, Watanabe K, Tamura T, Yamamoto S, Saijo N; Japan Clinical Oncology Group. Irinotecan plus cisplatin compared with etoposide plus cisplatin for extensive small-cell lung cancer. N Engl J Med. 2002; 346:85-91.

17. Lu ZH, Li J, Lu M, Zhang XT, Li J, Zhou J, Wang XC, Gong JF, Gao J, Li Y, Shen L. Feasibility and efficacy of combined cisplatin plus irinotecan chemotherapy for gastroenteropancreatic neuroendocrine carcinomas. Med Oncol. 2013; 30:664

18. Chung-Delgado K, Revilla-Montag A, GuillénBravo S, Ríos-Díaz H, Alva-Muñoz JC. Refractory thrombocytopenia responds to octreotide treatment in a case of evans syndrome with gastric neuroendocrine tumor. Case Rep Hematol. 2013; 2013:391086.

19. O'Toole D, Ducreux M, Bommelaer G, Wemeau JL, Bouché O, Catus F, Blumberg J, Ruszniewski P. Treatment of carcinoid syndrome: a prospective crossover evaluation of lanreotide versus octreotide in terms of efficacy, patient acceptability, and tolerance. Cancer. 2000; 88:770-776.

20. Villaume K, Blanc M, Gouysse G, Walter T, Couderc C, Nejjari M, Vercherat C, Cordier-Bussat M, Roche C, Scoazec JY. VEGF secretion by neuroendocrine tumor cells is inhibited by octreotide and by inhibitors of the PI3K/ AKT/mTOR pathway. Neuroendocrinology. 2010; 91:268278.

21. Tomassetti P, Migliori M, Corinaldesi R, Gullo L. Treatment of gastroenteropancreatic neuroendocrine tumours with octreotide LAR. Aliment Pharmacol Ther. 2000; 14:557-560.

22. Ducreux M, Ruszniewski P, Chayvialle JA, Blumberg J, Cloarec D, Michel H, Raymond JM, Dupas JL, Gouerou H, Jian R, Genestin E, Hammel P, Rougier P. The antitumoral effect of the long-acting somatostatin analog lanreotide in neuroendocrine tumors. Am J Gastroenterol. 2000; 95:3276-3281.

23. Rinke A, Müller HH, Schade-Brittinger C, Klose KJ, Barth P, Wied M, Mayer C, Aminossadati B, Pape UF, Bläker M, Harder J, Arnold C, Gress T, et al. Placebo-controlled, double-blind, prospective, randomized study on the effect of octreotide LAR in the control of tumor growth in patients with metastatic neuroendocrine midgut tumors: a report from the PROMID Study Group. J Clin Oncol. 2009; 27:4656-4663.

24. Chinese pathologic consensus group for gastrointestinal and pancreatic neuroendocrine neoplasms. Standardization in diagnosis of gastrointestinal and pancreatic neuroendocrine neoplasms: the Chinese consensus. Zhonghua Bing Li Xue Za Zhi. 2013; 42:691-694.

25. Yamaguchi $\mathrm{T}$, Machida N, Morizane C, Kasuga A, Takahashi H, Sudo K, Nishina T, Tobimatsu K, Ishido K, Furuse J, Boku N, Okusaka T. Multicenter retrospective analysis of systemic chemotherapy for advanced neuroendocrine carcinoma of the digestive system. Cancer Sci. 2014; 105:1176-1181.

26. Susini C, Buscail L. Rationale for the use of somatostatin analogs as antitumor agents. Ann Oncol. 2006; 17:17331742.

27. Caplin ME1, Pavel M, Ćwikła JB, Phan AT, Raderer M, Sedláčková E, Cadiot G, Wolin EM, Capdevila J, Wall L, Rindi G, Langley A, Martinez S, et al. Lanreotide in metastatic enteropancreatic neuroendocrine tumors. N Engl J Med. 2014; 371:224-33.

28. Zarogoulidis K, Eleftheriadou E, Kontakiotis T, Gerasimou G, Zarogoulidis P, Sapardanis I, Galaktidou G, Sakkas L, Gotzamani-Psarrakou A, Karatzas N. Long acting somatostatin analogues in combination to antineoplastic agents in the treatment of small cell lung cancer patients. 
Lung Cancer. 2012;76:84-8.

29. Scoazec JY, Couvelard A, Monges G, Leteurtre E, Belleannee G, Guyetant S, Duvillard P, Danjoux M, Parot X, Lepage C. Well-differentiated grade 3 digestive neuroendocrine tumors: myth or reality? The PRONET Study Group [abstract]. J Clin Oncol. 2012; 30: 15s (suppl; abstr 4129).

30. Vélayoudom-Céphise FL, Duvillard P, Foucan L, Hadoux J, Chougnet CN, Leboulleux S, Malka D, Guigay J, Goere D, Debaere T, Caramella C, Schlumberger M, Planchard D, et al. Are G3 ENETS neuroendocrine neoplasms heterogeneous? Endocr Relat Cancer. 2013; 20:649-657.
31. La Rosa S, Sessa F. High-grade poorly differentiated neuroendocrine carcinomas of the gastroenteropancreatic system: from morphology to proliferation and back. Endocr Pathol. 2014; 25:193-198.

32. Olsen IH, Sørensen JB, Federspiel B, Kjaer A, Hansen CP, Knigge U, Langer SW. Temozolomide as second or third line treatment of patients with neuroendocrine carcinomas. Scientific World Journal. 2012; 2012:170496.

33. Fonseca PJ, Uriol E, Galván JA, Alvarez C, Pérez Q, Villanueva N, Berros JP, Izquierdo M, Viéitez JM. Prolonged clinical benefit of Everolimus therapy in the management of high-grade pancreatic neuroendocrine carcinoma. Case Rep Oncol. 2013; 6:441-449. 